\title{
Acute pancreatitis following oesophagogastroduodenoscopy.
}

\author{
Nnamdi Arinze Nwafo
}

Rapid City Regional Hospital, Rapid City, South Dakota, USA

\section{Correspondence to}

Dr Nnamdi Arinze Nwafo, nnamdinwafo@gmail.com

Accepted 27 November 2017

\section{SUMMARY}

Acute pancreatitis is a well-recognised complication of endoscopic procedures like endoscopic retrograde cholangiopancreatography but not oesophagogastroduodenoscopy (OGD). I report a case of a 33-year-old woman, admitted with severe epigastric pain and vomiting 2 hours after an elective OGD for evaluation of chronic gastrointestinal symptoms. Pancreatitis was diagnosed on the basis of elevated lipase (40 $790 \mathrm{U} / \mathrm{L}$; normal 11-82) and findings on imaging studies. Other common causes of acute pancreatitis such as gallstones, alcohol and medications were ruled out. She had an extended hospital course because of severe disease, characterised by systemic inflammatory response syndrome, pleural effusion and ascites but was successfully managed conservatively with bowel rest, hydration and pain management. Acute pancreatitis should be considered a rare complication of $\mathrm{OGD}$ and should be considered in differential diagnosis for abdominal pain post OGD. Pathogenesis is likely from direct trauma to pancreas or gas insufflation.

\section{BACKGROUND}

Acute pancreatitis is an inflammatory condition of the pancreas characterised clinically by abdominal pain and elevated levels of pancreatic enzymes in the blood. ${ }^{1-3}$

Gallstones are the most common cause of acute pancreatitis, followed by alcohol ${ }^{4}$; other causes include hypertriglyceridaemia, hypercalcaemia, pancreatic malignancy, endoscopic retrograde cholangiopancreatography (ERCP), trauma, infectious agents, drugs, autoimmunity and heredity. ${ }^{4-6}$

Among endoscopic procedures, acute pancreatitis is a well-recognised complication of ERCP, occurring in about $1 \%$ of ERCP procedures. ${ }^{7}$ It is also a known complication of balloon enteroscopy, ${ }^{8-13}$ occurring in about $0.3 \%$ of double balloon enteroscopy (DBE) cases in a US retrospective study ${ }^{8}$ and $0.3 \%$ of DBE cases in a prospective study in Germany. ${ }^{9}$ Acute pancreatitis following oesophagogastroduodenoscopy (OGD) is however rare.

Presented here is the case of a 33-year-old woman who developed acute pancreatitis following an uneventful OGD.

\section{CASE PRESENTATION}

The patient is a 33-year-old woman with medical history that is remarkable for right lobe living liver transplant donation about 2 years earlier, during which time she also underwent a cholecystectomy.
Some time after liver donation, she developed persistent gastrointestinal complaints of uncertain aetiology. She reported generalised abdominal discomfort and pain that was most prominent in the epigastric and right upper quadrant area. She also had a sensation of numbness and tingling over the right upper quadrant area. Pain occurred daily but was not precipitated or exacerbated by food or fluid intake. She also reported nausea without vomiting, gurgling sensation in upper abdomen, abdominal bloating, constipation and straining while defecating.

She did not experience any significant weight loss. She tried gluten-free diet and low fermentable, oligo-, di-, monosaccharides, and polyols. (FODMAP) diet without significant change. She tried ranitidine, linaclotide, lubiprostone, probiotics and stool softeners without relief. She was eventually taken off all medications with the aim of providing clarity regarding potential implication of medications in her symptoms and was not on any prescription or over-thecounter medications at time of presentation. Prior laboratory workup (including thyroid function, liver/ biliary enzymes and pancreatic enzymes) was unremarkable. Abdominal ultrasound, pelvic ultrasound, abdominopelvic CT scan and MR enterography were non-revealing. Anorectal manometry was normal, and a colonoscopy was also non-revealing.

Patient was referred from a local emergency room after presenting with acute onset severe epigastric pain (different in character from prior abdominal pain) and vomiting that started about 2 hours after an elective OGD that was part of ongoing workup for her chronic gastrointestinal symptoms. She had no prior diagnosis of pancreatitis. She had no recent tobacco smoking, alcohol or recreational drug use history.

Vital signs at presentation were temperature $36.5^{\circ} \mathrm{C}$, pulse 74 , respiration 18 , blood pressure $132 / 89$ and oxygen saturation $97 \%$ on room air. Physical examination revealed a young, well-nourished woman in painful distress, equal and reactive pupils without scleral icterus, normal heart sounds without murmur or peripheral oedema, clear chest to auscultation, soft but diffusely tender abdomen with decreased bowel sounds and well-oriented patient with non-focal neurological examination.

\section{INVESTIGATIONS}

Laboratory workup was significant for lipase of $40790 \mathrm{U} / \mathrm{L}$ (normal 11-82), amylase of 6267 IU/L (normal 27-108), white blood cell count of $13.2 \times 10^{9} / \mathrm{L}$ (normal 4500-10 500), and haematocrit 


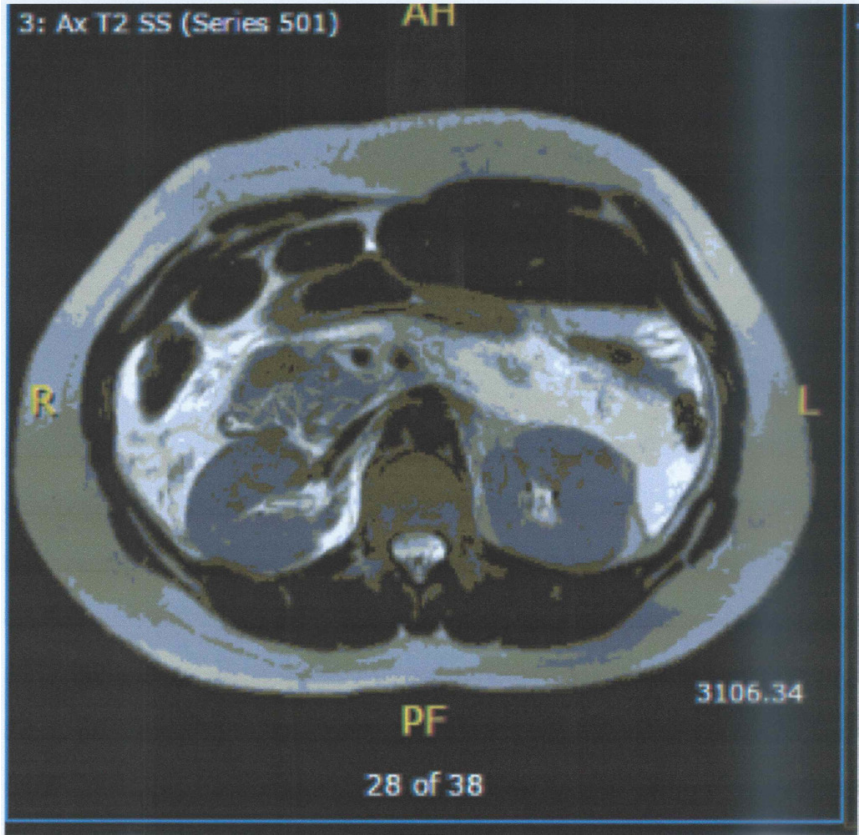

Figure 1 MR cholangiopancreatography showing extensive inflammation involving the pancreas and surrounding soft tissue, as well as large volume ascites in upper abdomen (cut 1).

of $40.8 \%$. Blood urea nitrogen $(12 \mathrm{mg} / \mathrm{dL})$, calcium $(8.8 \mathrm{mg} / \mathrm{dL})$ and triglyceride $(46 \mathrm{mg} / \mathrm{dL})$ levels were normal. Total bilirubin $(0.67 \mathrm{mg} / \mathrm{dL})$, alkaline phosphatase $(37 \mathrm{IU} / \mathrm{L})$, aspartate aminotransferase (26 IU/L) and alanine aminotransferase (18 IU/L) were also normal.

CT scan of abdomen and pelvis revealed evidence of acute pancreatitis and diffuse ascites. MR cholangiopancreatography (MRCP) showed large volume ascites in upper abdomen with extensive inflammation involving the pancreas and surrounding soft tissue, without evidence of necrosis and without bile duct

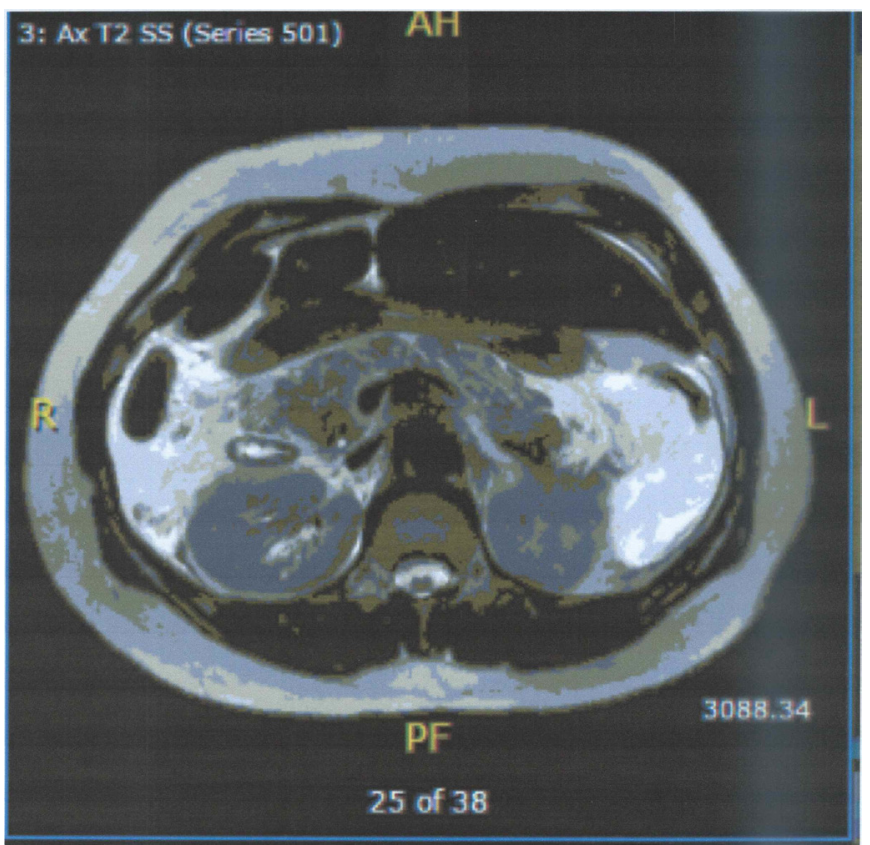

Figure 2 MR cholangiopancreatography showing extensive inflammation involving the pancreas and surrounding soft tissue, as well as large volume ascites in upper abdomen (cut 2).

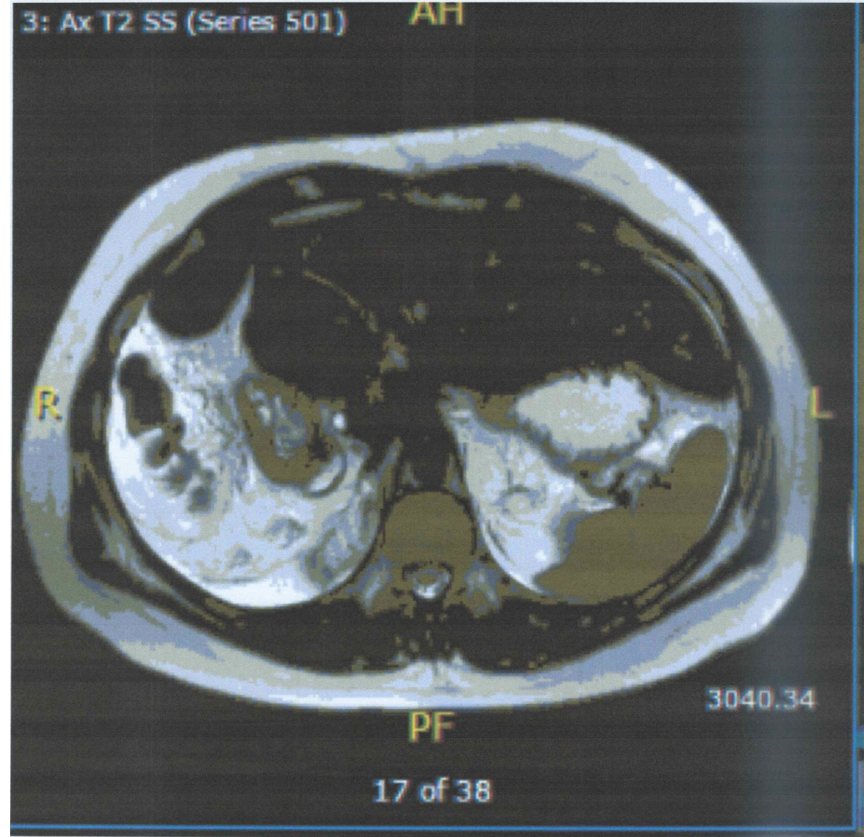

Figure 3 MR cholangiopancreatography showing extensive inflammation involving the pancreas and surrounding soft tissue, as well as large volume ascites in upper abdomen.

obstruction; evidence of donation of a portion of right lobe of the liver and compensatory left lobe hypertrophy were also noted (figures $1-3$ ).

The OGD itself revealed a non-bleeding gastric ulcer with no stigmata of bleeding. Pathology revealed mild chronic gastritis with focal metaplasia, but no dysplasia or neoplasia was identified; there were also no histological features for coeliac sprue or Helicobacter pylori organisms.

\section{TREATMENT}

Acute pancreatitis was diagnosed on the basis of presenting symptoms, elevated lipase and amylase levels, and findings on imaging studies. It was managed conservatively with bowel rest, intravenous fluid hydration, pain control and antiemetics. However, she developed bilateral pleural effusions with hypoxia, fever, tachycardia and persistent leucocytosis consistent with systemic inflammatory response syndrome (SIRS). She was treated empirically with intravenous piperacillin/tazobactam until a concomitant infective process was ruled out. Interval CT scan of abdomen and pelvis showed increased ascites in abdomen and pelvis, as well as increased inflammation involving the head and body of pancreas but without necrosis or focal pancreatic fluid collection.

\section{OUTCOME AND FOLLOW-UP}

Patient had an extended hospital course characterised by persistent severe upper abdominal pain that required treatment with hydromorphone patient-controlled analgesia and prolonged ileus. However, the SIRS resolved, and her condition eventually improved without need for invasive intervention. She was discharged home in improved health after a 12-day hospital stay.

She still had residual abdominal discomfort and pain at follow-up but did not show clinical, laboratory or imaging findings to suggest recurrent acute pancreatitis. She underwent an endoscopic ultrasound 3 weeks after discharge (and about 5 
weeks after initial OGD) that showed only a scar in the prepyloric region of the stomach (previous site of gastric ulcer noted on OGD), a pancreatic pseudocyst in the region of the head of the pancreas and many small peripancreatic lymph nodes with endosonographic appearance consistent with benign inflammatory changes. Biopsies were not performed to avoid precipitation or recurrence of acute pancreatitis. Interval imaging did show progressive reduction in size of pancreatic pseudocyst and peripancreatic lymph nodes.

\section{DISCUSSION}

OGD is an endoscopic procedure for visualisation of oropharynx, oesophagus, stomach and proximal duodenum, ${ }^{14}$ and can serve both diagnostic and therapeutic purposes in evaluation of upper gastrointestinal disorders. Complications are uncommon but include cardiopulmonary events, bleeding, perforation, infection and methemoglobinemia. ${ }^{7}{ }^{15}$ OGD is not a know cause of pancreatitis, though asymptomatic hyperamylasaemia or hyperamylasuria without clinical pancreatitis after endoscopy is recognised. ${ }^{16-18}$ However, a few cases of clinical pancreatitis occurring after OGD without ampulla cannulation have been documented, ${ }^{19-24}$ two of which also involved colonoscopies. ${ }^{2324}$ Clinical acute pancreatitis has also been reported following colonoscopies. ${ }^{23-28}$ In all the reported cases, the occurrence of symptoms and signs shortly after the procedures and the absence of other common causes of pancreatitis (such as gallstones, alcohol, etc), made the procedures the likely aetiology. Pathogenesis in these cases is unclear, but is believed to be from trauma to pancreas or duodenal or colonic gas insufflation in the region of pancreas, causing direct effect or an inflammatory response that leads to pancreatitis. On reviewing the cases, a pattern was more readily identifiable in case that involved colonoscopies, where anatomic locations of pancreatic involvement appeared to correlate with sites of resection and coagulation of polyps or areas of technical difficulties with colonoscopies.

Deschamps et al described a case of acute pancreatitis occurring after upper endoscopy for evaluation of anaemia in a 58-year-old woman with Grave's disease. ${ }^{19}$ A hiatal hernia without evidence of esophagitis was identified during the procedure, and an easily accessed duodenum was without any lesions. The patient experienced severe epigastric pain on withdrawal of endoscope into the antrum, but this then subsided. An hour after the procedure, however, she experienced severe right upper quadrant pain that radiated to the back. Evaluation was significant for low-grade fever, leucocytosis and elevated amylase $(800 \mathrm{mU} / \mathrm{mL}$, compared with normal of $<350)$. An abdominal X-ray did not show evidence of pneumoperitoneum or air-fluid level; advanced imaging such as abdominal ultrasound or CT abdomen was not performed. Symptoms persisted despite conservative management that included continuous gastric aspiration. Subsequent exploratory laparotomy revealed a $5 \mathrm{~cm}$ focus of acute necrotising pancreatitis behind the apex of the duodenal bulb and adjacent subserosal oedema but no duodenal or gastric perforation. No mucosal lesion was noted on duodenotomy, and cholangiography with manometry was normal. Postoperative course was reportedly favourable but was complicated by worsening of Grave's disease.

Wu and Hubbard reported the case of a 50-year-old man with Child-Pugh A cirrhosis and non-alcoholic steatohepatitis who underwent outpatient OGD to screen for gastro-oesophageal varices. ${ }^{20}$ The procedure, which was performed without difficulty and without need for intervention or biopsy, showed small oesophageal varices and erythema in gastric corpus and antrum, and the patient was discharged without immediate complications. Less than 2 days after procedure, however, he developed nausea, vomiting and new onset epigastric pain radiating to the back. He had elevated lipase (5966 U/L compared with normal range 73-350), elevated amylase (495 U/L compared with normal range 17-95) and inflammatory findings around the tail of the pancreas consistent with pancreatitis. Symptoms resolved and he was discharged home after 4 days.

Jabr reported the case of a 67-year-old female with history of paroxysmal atrial fibrillation on Coumadin, mild hyperlipidaemia, hypertension, type II diabetes and depression, admitted with Coumadin toxicity (international normalised ratio 18) and severe anaemia (haemoglobin $6.3 \mathrm{~g} / \mathrm{dL}$ ) in the setting of positive haemoccult test. ${ }^{22}$ Following resuscitation with packed red blood cell transfusion and reversal of coagulopathy, she underwent upper endoscopy that revealed several prepyloric ulcers without bleeding vessels and biopsies of the ulcers returning positive for H. pylori. She developed moderate to severe epigastric and left upper abdominal pain the day after upper endoscopy. Pancreatic enzymes (lipase and amylase) were initially normal but became elevated by the following day (lipase $894 \mathrm{U} / \mathrm{L}$ and amylase $250 \mathrm{U} / \mathrm{L})$. CT scan of abdomen showed evidence of pancreatitis in the pancreatic head. Symptoms progressively improved and patient was tolerating oral intake by the second day of onset of symptoms.

A 10-year-old girl with history of chronic pancreatitis who developed severe epigastric pain and intense vomiting 1 hour after upper endoscopy is another case reported in literature. ${ }^{21}$ Amylase and lipase were elevated to 2744 and $4350 \mu \mathrm{L}$ respectively, and an abdominal ultrasound revealed new 'pancreatic enlargement with hypo dense structure and trace of fluid' when compared with a study a few hour earlier. She recovered after 2 days of conservative management.

The case reported by Nevins and Keeffe involved an upper and lower endoscopy performed for evaluation of anaemia in a 69-year-old man with history of hypertension, gastro-oesophageal reflux disease and prior episode of diverticulosis. ${ }^{23}$ Upper endoscopy was unremarkable and was completed without need for biopsy or cannulation of the ampulla of Vater. A small sessile polyp was removed from the transverse colon with biopsy forceps and electrocautery without technical difficulties during colonoscopy. He returned home the same day, but within 18 hours of the procedure, he developed acute pancreatitis, diagnosed on the basis of mid-epigastric pain that radiated to the back, elevated amylase (593 IU/L) and changes on abdominal CT scan involving the body of pancreas (in close proximity to site of removal of the polyp), consistent with pancreatitis. This would suggest that pancreatitis might have been caused by polypectomy during colonoscopy rather than upper endoscopy. He improved over 3 days on conservative management with bowel rest, intravenous fluids, nasogastric tube placement to suction, antiemetics and pain control.

Ko et al described a case of pancreatitis after colonoscopy (and preceding upper endoscopy) for evaluation of iron-deficiency anaemia in a 60-year-old Caucasian woman with history of cadaveric renal transplant for hypertensive nephropathy. ${ }^{24}$ Upper endoscopy was unremarkable but difficulties were encountered advancing the colonoscope beyond the splenic flexure despite repositioning manoeuvres and application of external pressure during colonoscopy. An attempt to advance beyond this point with a gastroscope also failed. Two $6 \mathrm{~mm}$ polyps were removed by snare coagulation from the accessible area of the colon without apparent complications, but patient developed generalised cramping and mid-abdominal pain almost immediately 
after the procedure. Abdominal pain persisted till the following day and was associated with distension, constipation, nausea and poor oral intake. Laboratory workup was significant for leucocytosis and elevated amylase at $511 \mathrm{U} / \mathrm{L}$ (normal 30-105). Imaging studies confirmed multiple dilated loops of small and large bowel up to the area of non-specific thickening at the splenic flexure, consistent with ileus, as well as enlarged pancreatic tail adjacent to splenic flexure area, with significant mesenteric stranding and free fluid consistent with pancreatitis. Abdominal complaints and ileus (believed to have been caused by pancreatitis) persisted despite conservative management with intravenous fluids, prophylactic antibiotics and bowel rest (she declined nasogastric tube decompression), prompting repeat colonoscopy and placement of colonic decompression tube. A full colonoscopy was possible this time around and showed mild ischaemic changes in the ascending colon, without other structural abnormalities. She experienced significant relief in symptoms within 24 hours following repeat colonoscopy and recovered enough to be discharged over the next 2 days. The difficulties encountered with colonoscopy at splenic flexure and the involvement of adjacent pancreatic tissue in this case would again suggest that development of acute pancreatitis was related to colonoscopy rather than upper endoscopy.

Three other cases of acute pancreatitis occurring after colonoscopy reported technical difficulties with the procedures that may have caused pancreatic trauma or injury.

A 71-year-old man that underwent colonoscopy for surveillance for previous adenomatous polyps with low-grade dysplasia developed acute pancreatitis about 12 hours postprocedure..$^{25} \mathrm{~A}$ 10 and and $8 \mathrm{~mm}$ polyp had been removed with cold forceps from the right colon and proximal transverse colon, respectively. Removal of a large $25 \mathrm{~mm}$ polyp from the distal transverse colon was more challenging, requiring use of a snare and endocut, followed by argon plasma coagulation to eradicate fragments that were technically difficult to resect. Pancreatic inflammation seen on CT was limited to the pancreatic tail that was in close proximity to the distal transverse colon. Use of endocut was proposed to be cause of pancreatitis. The patient was discharged from hospital a week later after an uneventful recovery on conservative management.

A 25-year-old woman with history of right hemicolectomy for caecal adenocarcinoma also developed acute pancreatitis 4 hours after a technically difficult colonoscopy for evaluation of residual and synchronous lesions. ${ }^{26}$ The ascending colon could not be evaluated due to non-distension of bowel despite manoeuvring and increased air insufflation, but findings were otherwise unremarkable. Amylase (1500 IU/L; normal 40-140) and lipase (5121 IU/L; normal $0-160$ ) were elevated, but no advanced imaging was performed. Mechanical injury to the pancreas or excessive colonic insufflation was proposed mechanisms of pancreatitis in this case, and management was conservative.

The last published case of acute pancreatitis after colonoscopy was that of a 25-year-old man who developed acute pancreatitis 4 hours after undergoing colonoscopy for weight loss and diarrhoea. ${ }^{27}$ There was some difficulty advancing the scope beyond the splenic flexure, but this was eventually overcome after the scope was withdrawn and reintroduced, allowing visualisation up to the caecum; a $15 \mathrm{~mm}$ polyp was removed from the sigmoid colon.

In the case presented in this article, as in most of the previous cases summarised above, the occurrence of symptoms and signs shortly after the procedure and the absence of the common aetiologies of pancreatitis (gall stones, alcohol, hypercalcaemia, hypertriglyceridaemia, medications, etc) make OGD the likely cause of pancreatitis. Less common aetiologies like pancreatic divisium and sphincter of Oddi dysfunction (SOD) remain in consideration but also appear unlikely; there were no findings on CT scan, MRI, MRCP or follow-up endoscopic ultrasound to suggest pancreatic divisium, while the normal liver enzymes, absence of biliary duct dilation on imaging or prior gastrointestinal symptoms that were not consistent with biliary pain make diagnosis of SOD unlikely.

I agree with other authors that pathogenesis of pancreatitis is this case is likely from trauma to the pancreas, or duodenal or colonic gas insufflation in the region of pancreas, causing direct effect or an inflammatory response that leads to pancreatitis. Compared with the other reported cases, the case presented above was particularly severe (manifested by SIRS, pleural effusion, marked ascites and more extensive pancreatic involvement) and hospital course was protracted. The other case that appeared to be very severe and eventually required a laparotomy, ${ }^{19}$ one can argue that a more conservative approach may have been successful if more advanced imaging modalities that could have ruled out urgent or emergent complications were used. The reason for the level severity noted in this case remains unclear, even though the role of partial liver donation was considered. Whereas clinical acute pancreatitis is a known and often very serious complication in recipients of living donor liver transplants, ${ }^{29-32} \mathrm{I}$ did not come across much literature in way of acute pancreatitis occurring as a complication in liver donors, in whom the most common complications are biliary leaks, fistulas and strictures. ${ }^{33-37}$ Moving forward, in patients undergoing upper endoscopy, it may be worth bearing in mind a possible relationship between the severity of pancreatitis and liver donation with the resultant compensatory hypertrophy of the left lobe of the liver that presumably alters the hepatobiliary anatomy, despite the absence of documented precedence.

\section{Learning points}

- Oesophagogastroduodenoscopy (OGD) is not a known cause of clinical acute pancreatitis, but four previous published case reports have described acute pancreatitis after an OGD, while two others described acute pancreatitis following combined upper and lower endoscopy.

- Acute pancreatitis should be considered a rare potential complication of OGD, especially when occurring in the absence of other common causes of pancreatitis, and should be considered in differential diagnosis of abdominal pain occurring after OGD.

- This potential rare complication should be borne in mind in discussions when obtaining informed consent for the procedure.

Acknowledgements The author is grateful to Uchechukwu Megwalu and Nneka Obiokoye for the review and useful comments on the manuscript prior to submission.

Contributors The author drafted and critically revised the entire article including the case summary, literature review, discussion and conclusions.

Competing interests None declared.

Patient consent Obtained.

Provenance and peer review Not commissioned; externally peer reviewed.

(c) BMJ Publishing Group Ltd (unless otherwise stated in the text of the article) 2017. All rights reserved. No commercial use is permitted unless otherwise expressly granted.

\section{REFERENCES}

1 Sarles H. Pancreatitis symposium. Marseille: Basel SK, 1963. 
2 Singer MV, Gyr K, Sarles H. Revised classification of pancreatitis. Report of the Second International Symposium on the Classification of Pancreatitis in Marseille, France, March 28-30, 1984. Gastroenterology 1985;89:683-5.

3 Vege SS. UpToDateln: . Grover S, Etiology of acute pancreatitis. Waltham, MA: UpToDate, 2015

4 Kingsnorth A, O'Reilly D. Acute pancreatitis. BMJ 2006;332:1072-6.

5 Whitcomb DC. Acute pancreatitis. N Engl J Med Overseas Ed 2006;354:2142-50.

6 Forsmark CE, Baillie J. AGA Institute technical review on acute pancreatitis. Gastroenterology 2007;132:2022-44.

7 Hart R, Classen M. Complications of diagnostic gastrointestinal endoscopy. Endoscopy 1990;22:229-33.

8 Gerson LB, Tokar J, Chiorean M, et al. Complications associated with double balloon enteroscopy at nine US centers. Clin Gastroenterol Hepatol 2009;7:1177-82.

9 Möschler O, May A, Müller MK, et al. Complications in and performance of doubleballoon enteroscopy (DBE): results from a large prospective DBE database in Germany. Endoscopy 2011;43:484-9.

10 Möschler O, May AD, Müller MK, et al. Complications in double-balloon-enteroscopy: results of the German DBE register. Z Gastroenterol 2008;46:266-70.

11 Xin L, Liao Z, Jiang YP, et al. Indications, detectability, positive findings, total enteroscopy, and complications of diagnostic double-balloon endoscopy: a systematic review of data over the first decade of use. Gastrointest Endosc 2011;74:563-70.

12 Groenen MJ, Moreels TG, Orlent $\mathrm{H}$, et al. Acute pancreatitis after double-balloon enteroscopy: an old pathogenetic theory revisited as a result of using a new endoscopic tool. Endoscopy 2006;38:82-5.

13 Yip WM, Lok KH, Lai L, et al. Acute pancreatitis: rare complication of retrograde single-balloon enteroscopy. Endoscopy 2009;41(Suppl 2):E324.

14 Cohen J, Greenwald DA. Grover S, Overview of upper gastrointestinal endoscopy. Waltham, MA: UpToDate, 2015. (accessed July 2017).

15 Ben-Menachem T, Decker GA, Early DS, et al. Adverse events of upper GI endoscopy. Gastrointest Endosc 2012;76:707-18.

16 Lifton L, Brooks C, Rosson R, et al. The effect of UGI endoscopy on serum amylase. Gastroenterology 1975;68:936.

17 Kobayashi T, Fukuchi S, Sawano S, et al. Changes in serum isoamylase activities after fibergastroduodenoscopy and colonoscopy. Isoamylase after FGDS and FCS. Endoscopy 1979;11:133-7.

18 Blackwood WD, Vennes JA, Silvis SE. Post-endoscopy pancreatitis and hyperamylasuria. Gastrointest Endosc 1973;20:56-8.

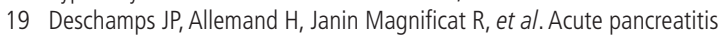
following gastrointestinal endoscopy without ampullary cannulation. Endoscopy $1982 ; 14: 105-6$
20 Wu P, Hubbard H. Acute pancreatitis after upper endoscopy. Case Rep Intern Med 2016;3:41-3.

21 Iwańczak B, Stawarski A, Hutyra T, et al. [Acute pancreatitis as a complication of diagnostic gastroduodenal endoscopy at 10 years old girl-case report]. Pol Merkur Lekarski 2008;24:20-2.

22 Jabr Fl, Doctor Quest. Acute pancreatitis after upper endoscopy. http://www.questdoc. com/acutepancreatitis.htm

23 Nevins AB, Keeffe EB. Acute pancreatitis after gastrointestinal endoscopy. J Clin Gastroenterol 2002;34:94-5.

$24 \mathrm{Ko} \mathrm{HH}$, Jamieson T, Bressler B. Acute pancreatitis and ileus post colonoscopy. Can J Gastroenterol 2009;23:551-3.

25 Fortea Jl, Marín Jimenez I, Nogales Rincon 0, et al. Postcolonic polypectomy pancreatitis. Endoscopy 2010;42 Suppl 2:E221-E222.

26 Shekhar S, Singh S, Gupta S, et al. Postcolonoscopy pancreatitis. Endoscopy 2014:46:E515-16.

27 Thomas AW, Mitre RJ. Acute pancreatitis as a complication of colonoscopy. J Clin Gastroenterol 1994;19:177-8.

28 Khashram M, Frizelle FA. Colonoscopy-a rare cause of pancreatitis. N Z Med J 2011;124:74-6.

29 Danalıoğlu A, Mitchell OJ, Singh VK, et al. Acute pancreatitis following adult liver transplantation: a systematic review. Turk J Gastroenterol 2015;26:450-5.

30 Krokos NV, Karavias D, Tzakis A, et al. Acute pancreatitis after liver transplantation: incidence and contributing factors. Transp/ Int 1995;8:1-7.

31 Yanaga K, Shimada M, Gordon RD, et al. Pancreatic complications following orthotopic liver transplantation. Clin Transplant 1992;6:126-30.

32 Alexander JA, Demetrius AJ, Gavaler JS, et al. Pancreatitis following liver transplantation. Transplantation 1988;45:1062-5.

33 Gad EH, Alsebaey A, Lotfy M, et al. Complications and mortality after adult to adult living donor liver transplantation: A retrospective cohort study. Ann Med Surg 2015;4:162-71.

34 Renz JF, Roberts JP. Long-term complications of living donor liver transplantation. Liver Transp/ 2000;6(6 Suppl 2):s73-6.

35 Lo CM. Complications and long-term outcome of living liver donors: a survey of 1,508 cases in five Asian centers. Transplantation 2003;75(3 Suppl):S12-15.

36 Simoes $P$, Kesar V, Ahmad J. Spectrum of biliary complications following live donor liver transplantation. World J Hepatol 2015;7:1856-65.

37 Wang SF, Huang ZY, Chen XP. Biliary complications after living donor liver transplantation. Liver Transp/ 2011;17:1127-36.

Copyright 2017 BMJ Publishing Group. All rights reserved. For permission to reuse any of this content visit

http://group.bmj.com/group/rights-licensing/permissions.

BMJ Case Report Fellows may re-use this article for personal use and teaching without any further permission.

Become a Fellow of BMJ Case Reports today and you can:

- Submit as many cases as you like

- Enjoy fast sympathetic peer review and rapid publication of accepted articles

- Access all the published articles

- Re-use any of the published material for personal use and teaching without further permission

For information on Institutional Fellowships contact consortiasales@bmjgroup.com

Visit casereports.bmj.com for more articles like this and to become a Fellow 